\title{
Detection of a concomitant distal deletion in an inverted duplication of chromosome 3. Is there an overall mechanism for the origin of such duplications/deficiencies?
}

\author{
J utta J enderny ${ }^{1}$, M icaela Poetsch ${ }^{1}, M$ aria H oeltzenbein ${ }^{1}$, U rsula Friedrich ${ }^{2}$ and \\ A nna Jauch ${ }^{3}$ \\ ${ }^{1} D$ epartment of H uman G enetics, University of K iel, G ermany \\ ${ }^{2}$ Institute of H uman G enetics, A arhus U niversity, A arhus, D enmark \\ ${ }^{3}$ Institute of $\mathrm{H}$ uman $\mathrm{G}$ enetics, U niversity of $\mathrm{H}$ eidelberg, G ermany
}

\begin{abstract}
We describe the first inverted duplication of the p21.3p26 region of chromosome 3 in a child with phenotypic features of the trisomy $3 p$ syndrome. This uncommon type of aberration was verified by multicolour fluorescence in situ hybridisation (FISH) using yeast artificial chromosome (YAC) clones from chromosome 3 (CEPH library). With a newly constructed YAC clone from the 3 p26 region an unexpected subtelomeric deletion was diagnosed in the aberrant chromosome 3. Using the primed in situ labelling (PRINS) method, telomeres were found to be present on the recombinant chromosome 3 . The repeated appearance of concomitant distal deletions in inverted duplications suggests that an overall mechanism exists for the origin of such duplications/ deficiencies.
\end{abstract}

Keywords: inverted duplication; deletion; chromosome 3; fluorescence in situ hybridisation; YAC clones

\section{Introduction}

Cases of an inverted duplication of the short arm of a chromosome in association with a deficiency distal to the duplication itself have been reported for chromosomes $8,{ }^{1-8} 9,{ }^{9}$ and $7 .{ }^{10}$ To define the location of the rearrangement breakpoints more precisely, Floridia et

Correspondence: D r Jutta J enderny, I nstitute of I mmunology, Pathology and Molecularbiology, Department of Human G enetics, L ademannbogen 61-63, $22339 \mathrm{H}$ amburg, G ermany. Tel: + 4940 53805810; Fax: + 4940 53805803; E-mail: jenderny@mail.labor-keeser-arndt.de

Received 15 October 1998; revised 16 February 1998; accepted 6 A pril 1998 $\mathrm{al}^{8}$ demonstrated by extensive molecular analysis that the inverted $8 p$ duplications of all 16 cases studied were consistently accompanied by a subtelomeric deletion of the region spanning from D8S349 to the telomere. Teebi et al ${ }^{9}$ reported a simultaneous deletion of p22pter in an inverted duplication of the short arm of chromosome 9 detected by the combined application of high resolution trypsin $\mathrm{G}$ banding and fluorescence in situ hybridisation (FISH) analysis. A similar type of an aberrant rearrangement resulting in a duplication was reported in the long arm of one chromosome 7(q21.2q36) in a second trimester foetus. ${ }^{10}$ Part of band q36 was apparently deleted as shown by the absence of hybridisation with the DNA probe D 7S427. 
We report on a de novo inverted duplication of chromosome 3 . On the basis of cytogenetic studies alone, the proposita had the karyotype $46, X X$, inv dup(3)(p21.3p26). Since complex mutational events associated with a de novo inverted duplication have been observed in three different chromosomes, we assumed that distal deletions might be a common feature of such rearrangements. Therefore we performed an extensive molecular cytogenetic analysis with DNA probes spanning the short arm of chromosome 3.

\section{Methods}

\section{Patient}

The proband exhibited many of the main clinical manifestations of the partial trisomy $3 p$ syndrome: psychomotor retardation, microcephaly, square-shaped face, frontal bossing, temporal indentation, prominent cheeks, hypertelorism or telecanthus, down-turned corners of the mouth, cleft lip and palate, eversion of lips, micrognathia/retrognathia, short neck and congenital heart disease.(see reviews ${ }^{11,12}$ ) No apparent phenotypic abnormality related to the monosomy $3 p$ syndrome was observed.

\section{Cytogenetic Analysis}

Chromosome analysis was performed on PHA stimulated lymphocytes using standard trypsin $\mathrm{G}$ banding techniques.

\section{Chromosome Painting}

Chromosome in situ suppression (CISS) hybridisation was performed with a whole painting D NA probe of chromosome 3 (A GS, H eidelberg, Germany) on metaphase spreads from the patient. The conditions used for hybridisation and detection of the resultant signal by an antibody/peroxidase system were described by Stock et al. ${ }^{13}$

\section{Probes}

Two yeast artificial chromosome (YAC) clones (806A 7, 938G 11) from the short arm of chromosome 3 were obtained from the Centre d'Etude du Polymorphisme Humain (CEPH) library. Information on the Y A C s can be found in the Genome Data Base. The YAC clone TYAC 148, ${ }^{14}$ which mapped to $3 p 26$, was constructed and screened with the human specific telomere sequence TTAGGG. It was kindly provided by $\mathrm{Helen}$ Donis-K eller (Washington University School of Medicine, St L ouis, USA ).

\section{Alu PCR}

The agarose plugs containing the YAC DNA were prepared as described by Sheehan and Weiss, ${ }^{15}$ with minor modifications. B riefly, yeast cells were grown to $O D_{600}=7$ in SD medium $^{16}$ and washed in ET buffer $(10 \times \mathrm{ET}$ : $100 \mathrm{~mm}$ Tris $\mathrm{HCl}, 500 \mathrm{~mm}$ EDTA, pH 7.5). Cells were spheroplasted with Iyticase (L-8012, Sigma, D eisenhofen, G ermany), embedded in $1 \%$ low melting point agarose solution ( $G$ ibcoBRL, E ggenstein, G ermany) and put into plug moulds. A fter 20 min hardening at $4^{\circ} \mathrm{C}$, the plugs were removed from the moulds and incubated at $60^{\circ} \mathrm{C}$ in $\mathrm{ET}$ buffer containing $5 \%$ SD $S$ for
$2 \mathrm{~h}$, followed by incubation in the same buffer containing proteinase K (P-6556, Sigma, Germany) instead of SD S at $50^{\circ} \mathrm{C}$ overnight. A fter three washes in $\mathrm{ET}$ buffer, the plugs were stored at $4^{\circ} \mathrm{C}$. The FISH probes were prepared from the YAC plugs by means of A lu-PCR, as described by Lengauer et al. ${ }^{17}$ The PCR products were biotinylated (B ioPrime- $K$ it, G ibcoBRL, Germany) or digoxigenin labelled (DIG -D NA $\mathrm{L}$ abeling- $\mathrm{K}$ it, $\mathrm{B}$ oehringer $\mathrm{M}$ annheim $\mathrm{G} \mathrm{mbH}$, M annheim, Germany) by random primed labelling according to the manufacturer's instructions.

\section{Fluorescence in situ hybridisation with YAC clones}

For FISH, the techniques of Pinkel et al ${ }^{18}$ and Lengauer et $\mathrm{al}^{17}$ were modified. A small amount $(2 \mu \mathrm{l})$ of hybridisation mix (per $\mu$ l: 10ng of each of the two differently labelled YAC probes, $10 \mu \mathrm{g}$ of unlabelled human Cot 1 DNA, $50 \%$ formamide, $10 \%$ dextran sulfate and $1 \times \mathrm{SSC}, \mathrm{pH} 7.5$ ) was placed on the cell containing area of the slides, which was covered with a round $10 \mathrm{~mm}$ cover slip and sealed with rubber cement. The slides were denatured for $5 \mathrm{~min}$ at $75^{\circ} \mathrm{C}$ and hybridised overnight at $37^{\circ} \mathrm{C}$. Post-hybridisation washes were performed three times in $0.1 \times \mathrm{SSC}$ at $60^{\circ} \mathrm{C}$ for $7 \mathrm{~min}$. In multicolour FISH experiments biotin and digoxigenin conjugated probes were detected simultaneously by a mixture of Cy3 conjugated avidin (red fluorochrome) (Dianova, $\mathrm{H}$ amburg, Germany) and FITC conjugated anti-digoxigenin (green fluorochrome) (Boehringer $M$ annheim $\mathrm{G} \mathrm{mbH}$, Mannheim, Germany), followed by a mixture of anti-avidin (C amon, Wiesbaden, Germany) and monoclonal mouse antiFITC (DA KO, H amburg, G ermany). A third layer included a mixture of $\mathrm{Cy} 3$ conjugated avidin and FITC-conjugated donkey anti-mouse (D ianova, $\mathrm{H}$ amburg, Germany). A mplification was performed by repeating the last two detection steps. Chromosomes were counterstained with $1 \mu \mathrm{g} / \mathrm{ml}$ 4',6-diamidino-2-phenylindole-dihydrochloride (DAPI, Sigma, Germany). Slides were mounted in antifade solution $10.2 \%$ p-phenylenediamine dihydrochloride, Sigma, in $80 \%$ glycerol, $20 \mathrm{mM}$ Tris- $\mathrm{HCl}, \mathrm{pH}$ 8.0). Signals were visualised with a ZEISS Axiophot fluorescence microscope (Z eiss, O berkochem, Germany) by changing the filter sets 09 (FITC), 00(Cy3) and 02(DAPI), and digitised for documentation with the ISIS system (M etasystems, Sandhausen, Germany). Ten metaphase spreads were analysed for each FISH experiment.

\section{Primed in situ labelling}

The telomeres were visualised with the primed in situ (PRINS) labelling method, as described in detail by Therkelsen et $\mathrm{al}^{19}{ }^{19}$ using the telomere sequence (CCCTA A $)_{7}$ as primer.

\section{Results}

\section{Cytogenetic Analysis}

A II 30 analysed metaphases from the child revealed the karyotype 46,XX,invdup(3)(p21.3p26)(Figure 1). Both parents had normal karyotypes.

\section{Chromosome Painting}

A fter CISS hybridisation with a whole painting probe of chromosome 3 , both the normal chromosome 3 and 


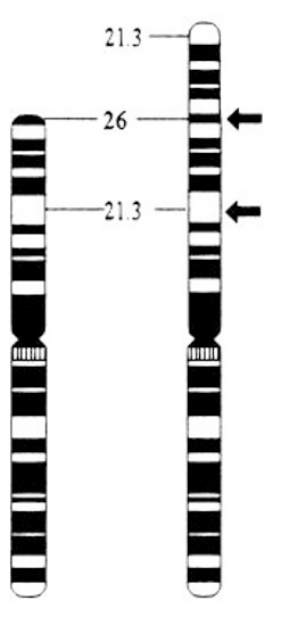

3
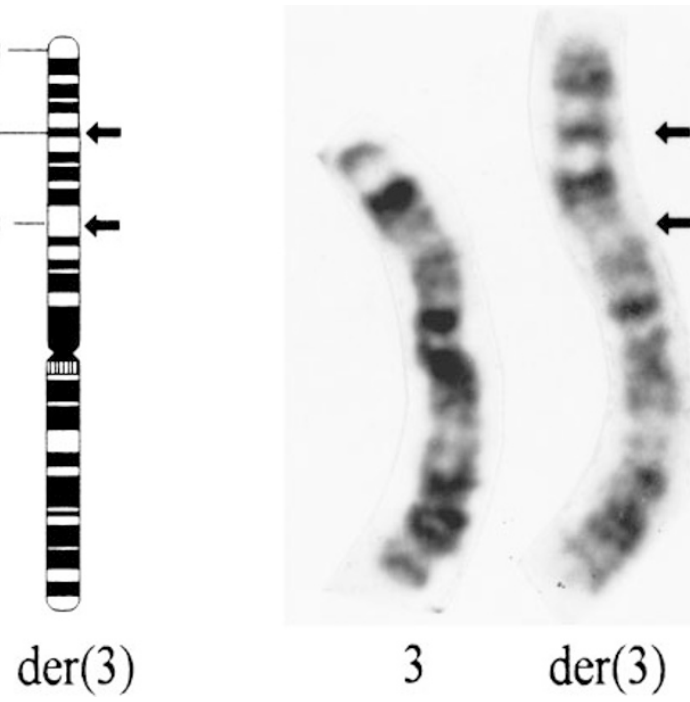

Figure 1 Trypsin $G$ banding of chromosomes from the female carrier showing the inv dup(3)(p21.3p26). I diograms of the normal chromosome 3 and the recombinant chromosome 3 are shown on the left, high resolution banding of the chromosomes 3 (IARC: 600 bands) on the right. The inverted duplication is indicated by two arrows.

the recombinant chromosome 3 showed clear, uninterrupted hybridisation signals. Therefore the additional chromosome material in the short arm must have been of chromosome 3 origin (Figure 2a).

\section{FISH using YAC clones}

In multicolour FISH, the YAC clone 806A 7 hybridised more telomerically (green hybridisation signals) than the YAC clone 938G 11 (red hybridisation signals) in the normal chromosome 3 (cen-938G 11-806A 7-tel), whereas in the aberrant chromosome 3 the two YACs had the following order: cen-938G 11-806A 7-806A 7938G 11-tel (Figure $2 b$ ). In single FISH the YAC clone 806A 7 mapped to 3p26 and the YAC clone 938G 11 to p22p23, respectively (data not shown). The newly constructed YAC clone TYAC148 hybridised to the most distal region of the short arm of chromosome 3 in the band p26. Hybridisation of this YAC clone (in combination with YAC 806A 7) to the chromosomes of the child, however, gave a single hybridisation signal only on the normal chromosome 3 and not on the aberrant chromosome 3 . The validity of this result was confirmed in ten patient metaphases which all gave the same result (Figure 2c).

\section{PRINS}

By the PR INS labelling technique it was shown that the telomeres were present in all chromosomes (Figure 2d).
A s the data accumulated, it became apparent that the recombinant chromosome 3 had a partial duplication $3 p$ as well as a deletion of $3 p 26$, the karyotype being 46,XX ,invdup(3) (qter >p26::p26->p21.3::p26), $\operatorname{del}(3)(p 26)$.

\section{Discussion}

Three mechanisms have been proposed to explain the origin of inverted duplication chromosomes leading to partial monosomy and partial trisomy. (see reviews ${ }^{5,8}$ ) Weleber et al ${ }^{1}$ suggested that an unusual intrachromosomal meiotic recombination occurs in two homologous chromosomes (Figure 3a). This is an initial event in which the ends of the two symmetric broken chromosomes fuse together. The recombination process is called a $U$-type exchange (Figure $3 b$ ) and creates a dicentric chromosome (Figure 3c). A fter division one daughter cell contains a recombinant chromosome with one centromere and a region with a symmetric inverted duplication accompanied by a concomitant distal deficiency together with the lack of telomeric sequences (Figure 3d).

$\mathrm{New}$ data on inverted $8 p$ duplications/deficiencies proposed a similar, but modified mechanism. During pairing an abnormal misalignment occurs between two homologous chromosomes, which is followed by an abnormal crossover (Figure 3e). H owever, the resulting dicentric chromosome is not symmetric, since the duplicated regions are separated by a single copy region (Figure 3f). During the subsequent anaphase $I$, breakage can occur at the centromere or anywhere in the short arm region between the two centromeres of the dicentric chromosome, forming two different chromosomes either with one centromere or with a second centromere at the tip of the short arm (Figures $3 \mathrm{~g}$ and 3h). ${ }^{8}$ In contrast to the lack of telomeric sequences as proposed by Weleber et al, ${ }^{11} \mathrm{Floridia}$ et $\mathrm{al}^{8}$ observed new telomeres after FISH with the all-human telomeres probe (Onkor).

A $n$ alternative mechanism involving an inverted duplication with partial monosomy was favoured by $\mathrm{G}$ orinati et al. ${ }^{20} \mathrm{This}$ more complex interaction includes two abnormal events: a paracentric inversion is found in the short arm of a chromosome in one parent. During meiosis the chromosome carrying the paracentric inversion together with its normal homologous chromosome forms an inversion loop. A crossing-over occurs in the inversion loop and the repair process creates a $U$-type exchange. A fter division the daughter 
cell contains a monocentric recombinant chromosome with an inverted duplication region and a concomitant distal deficiency together with normal telomeric sequences (the other daughter cell contains a chromosome with an interstitial deletion). We did not detect a paracentric inversion in our patient's parents' chromosomes. Nevertheless, we observed an inverted duplication of the $3 p 21 p 26$ region accompanied by a subtle deletion distal to the cytogenetically proposed 3p26 breakpoint and telomeric repeats (Figure 3f). Therefore we favour either a symmetric or asymmetric recombination process involving the main steps (Figure 3) as discussed by Weleber et al ${ }^{1}$ or Floridia. ${ }^{8} \mathrm{O}$ ur findings

a

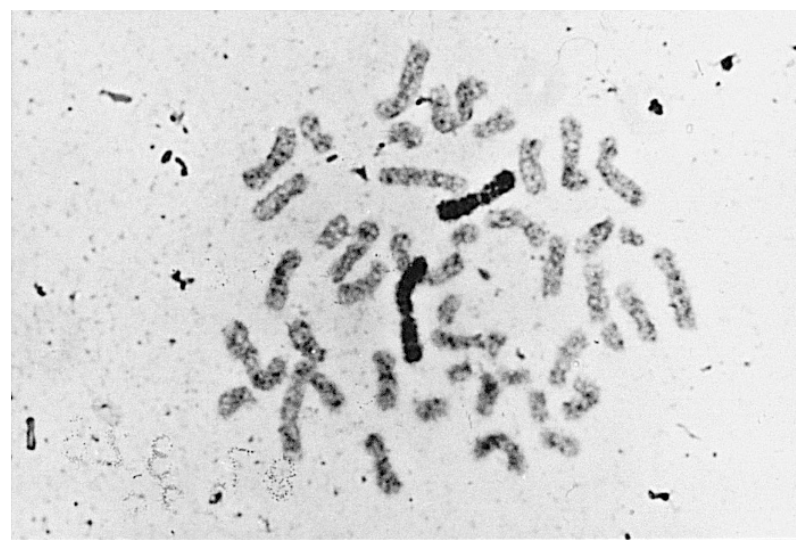

C

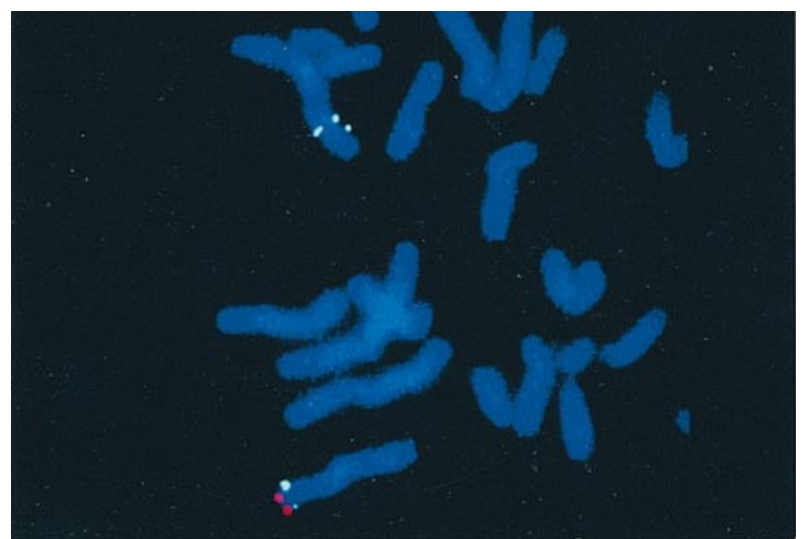

that telomeres were found to be present on broken chromosomes are in agreement with the study of Floridia et al ${ }^{8}$ and with several other reports. ${ }^{10,21}$

Theoretically our patient should express clinical symptoms of both the trisomy $3 p$ syndrome because of the duplication of the 3p21p26 region, and the monosomy $3 p$ syndrome because of the deletion in 3p26. The characteristic growth retardation and ptosis seen in patients with the monosomy $3 p$ syndrome are lacking in our patient, whereas the main features of the trisomy $3 p$ syndrome, i.e. the typical square-shaped face and temporal indentations, are present. Most of the other symptoms of these two syndromes overlap, namely

b

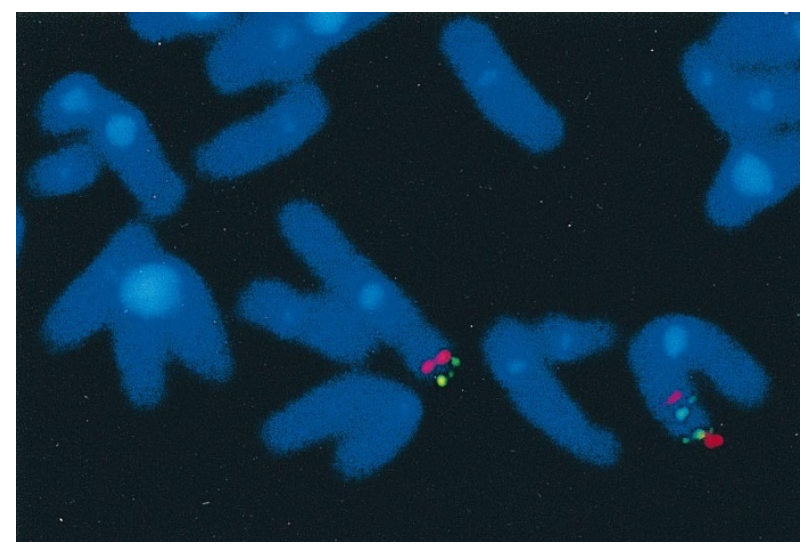

d

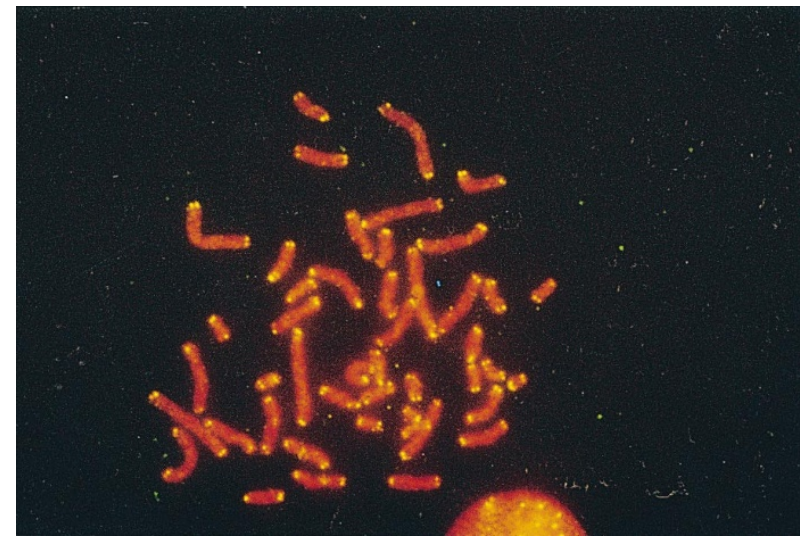

Figure 2 (a) Metaphase from the patient showing the normal chromosome 3 and the recombinant chromosome 3 after in situ hybridisation with a painting probe of chromosome 3 ( $A G S$, H eidelberg, G ermany) using indirect peroxidase with diaminobenzidine staining and hematoxylin-eosin counterstain. (b) Partial metaphase after multicolour in situ hybridisation with the YAC clone 806A 7 (green hybridisation signals) and theYAC clone 938G 11 (red hybridisation signals). (c) Partial metaphase after multicolour FISH with the YAC clone 806A 7 (green hybridisation signals) and the subtelomerspecific YAC clone TYAC 148 (red hybridisation signals). The aberrant chromosome 3 does not show any signal with the YAC clone TYAC 148, whereas the normal chromosome 3 has one signal. (d) The telomeres of all chromosomes were visualised with the PRINS labelling method. 
mental retardation, microcephaly, micrognathia, congenital heart disease, gastrointestinal malformation, and renal abnormalities. ${ }^{11,12,22,23}$

It is interesting to note that the deletion related to TYAC 148 has a size of $300 \mathrm{~Kb}$ and includes not only repeated sequences but also the chromosome-specific STS SAKB 8, indicating the presence of heteropolymorphism of chromosome telomere regions. The cytogenetic breakpoint associated with the monosomy $3 p$ syndrome has been identified at band p25. A ccording to our data the inverted $3 p$ duplication shared a more distal p26 deletion, perhaps resulting in the lack of any additional detectable phenotypic consequences. I n fact, a 3p25.3 terminal deletion with no apparent abnormalities has been demonstrated in a mother and her child. $^{24}$

Similarly, a characteristic phenotype associated with deletions at $7 q 36$ was not found in a second trimester foetus with an inverted duplication of chromosome 7 in association with a deletion within $7 q 36 .{ }^{10} \mathrm{H}$ owever, the loss of the DEF1 gene in all cases of inverted $8 p$ duplication/deficiencies supports the assumption that during the process of repair of an aberrant recombination, important genes are both duplicated and deleted. In addition, the loss of the distal 9p26 region in an inverted duplication made a detectable contribution to the phenotype, because the presence of upslanting palpebral fissures and dolichomesopalangy in the patient was in agreement with the diagnosis of a monosomy 9p syndrome.

In conclusion, precise characterisation of the recombinant chromosome 3 was possible by the combined application of cytogenetics and various molecular cytogenetic techniques. Concomitant deletions due to an inverted duplication are most probably more frequent than cytogenetic methods alone have been able
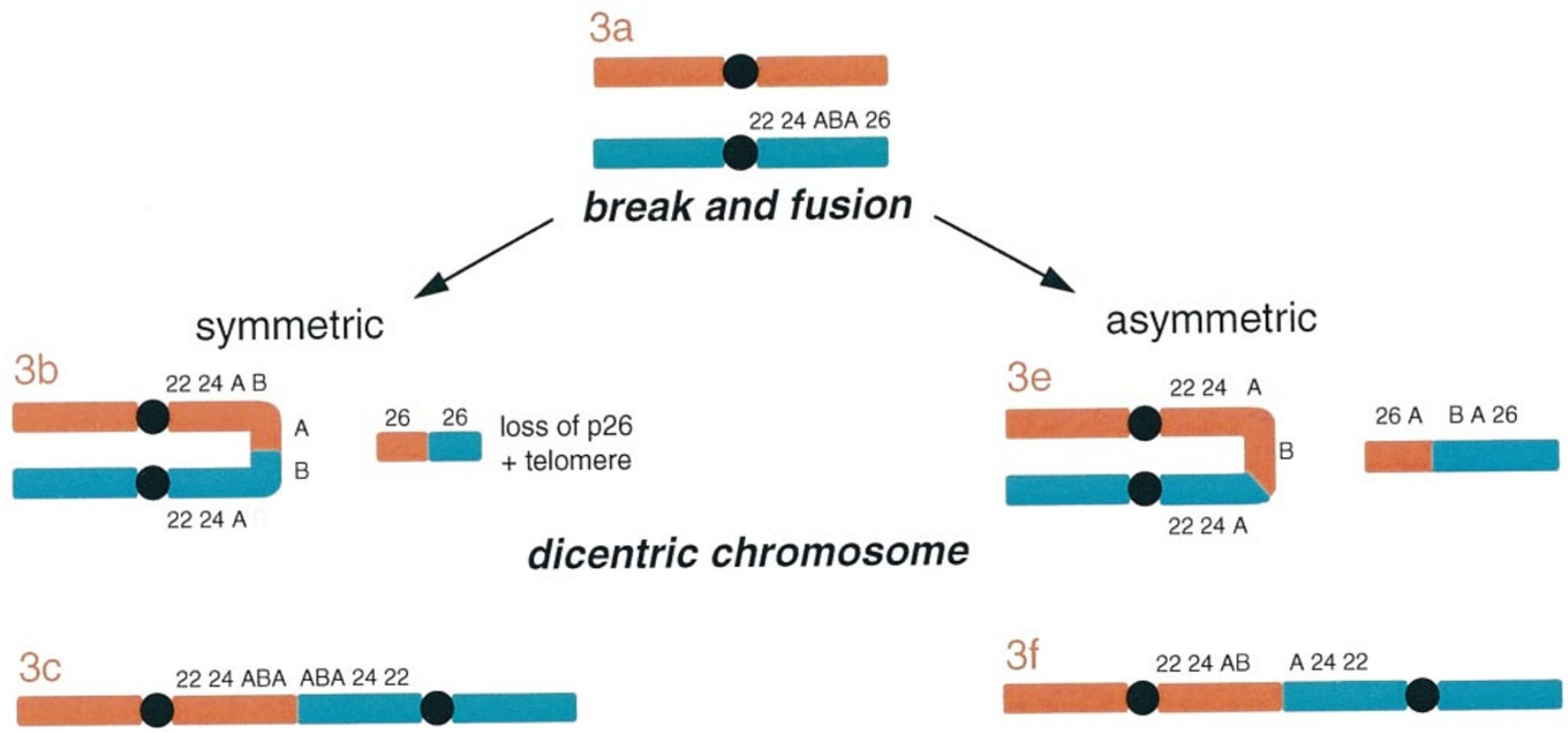

\section{break in anaphase}
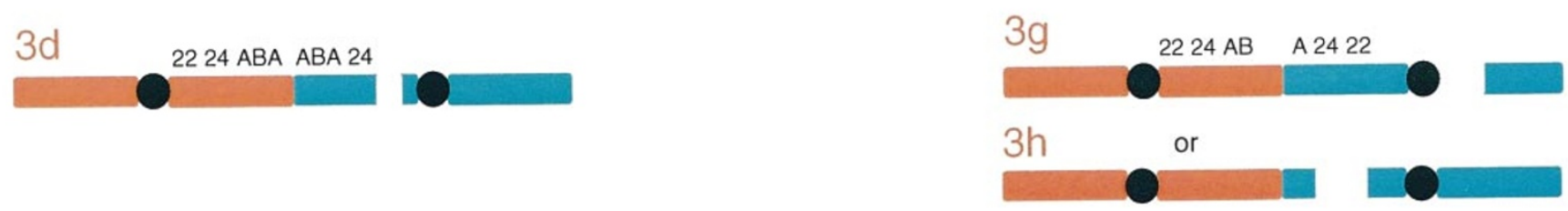

\section{telomere regeneration}

Figure 3 Schematic presentation of a classical (Weleber et $\mathrm{al}^{1}$ ) and modified (Floridia et $\mathrm{al}^{8}$ ) proposed mechanism to explain the origin of a de novo inverted duplication chromosome with a concomitant deletion (see Discussion). 
to demonstrate. The occurrence of the complex rearrangement in a further chromosome suggests that an overall mechanism exists for such inverted duplications leading to partial trisomy and partial monosomy.

\section{Acknowledgements}

We are grateful to Helen Donis-Keller (Washington U niversity School of Medicine, St Louis, MO 63110, USA) for providing the subtelomeric YAC clone TYA C 148. Part of this study was supported by a European grant to $\mathrm{T}$ Cremer (associated contract No ERBCRXCT 930177).

\section{References}

1 Weleber RG, Verma R S, K imberling WJ, Fieger HG, L ubs $\mathrm{HA}$ : D uplication-deficiency of the short arm of chromosome 8 following artificial insemination. A nn G enet 1976; 19: 241-247.

2 Dill FJ, Schertzer M, Sandercock J, Tischler B, Wood S: Inverted tandem duplication generates a duplication deficiency of chromosome 8p. Clin Genet 1987; 32: 109-113.

3 Henderson KG, Dill FJ, Wood S: Characterization of an inversion duplication of the short arm of chromosome 8 by fluorescent in situ hybridization. A m J M ed G enet 1992; 44: 615-618.

4 Minelli A, Floridia G, Rossi E et al: D 8S7 is consistently deleted in inverted duplications of the short arm of chromosome 8 (inv dup 8). Hum Genet 1993; 92: 391-396.

5 Engelen JJM, De Die-Smulders CEM, Fryns JP et al: Partial trisomy and monosomy $8 p$ due to inversion duplication. Clin G enet 1994; 45: 203-207.

6 Barber J CK, James R S, Patch C, Temple I K : Protelomeric sequences are deleted in cases of short arm inverted duplication of chromosome 8. A m J M ed G enet 1994; 50: 296-299.

7 G uo WJ, Callif-D aley F, Z apata M C, M iller ME: Clinical and cytogenetic findings in seven cases of inverted duplication of $8 p$ with evidence of a telomeric deletion using fluorescence in situ hybridization. A $\mathrm{m}$ J M ed G enet 1995; 58: 230-236.

8 Floridia G, Piantanida M, Minelli A et al: The same molecular mechanism at the maternal meiosis produces mono- and dicentric $8 p$ duplications. A m J Hum Genet 1996; 58: 785- 796
9 Teebi A S, Gibson L, McG rath J, M eyn MS, B reg WR, Yang-Feng TL: Molecular and cytogenetic characterization of 9p- abnormalities. A m J M ed Genet 1993; 46: 288-292.

10 Stetten G, Charity LL, Kasch LM et al: A paternally derived inverted duplication of $7 q$ with evidence of a telomeric deletion. A m J M ed G enet 1997; 68: 76-81.

11 Charrow J, Cohen MM, Meeker D: Duplication 3p syndrome: report of a new case and review of the literature. A m J M ed G enet 1981; 8: 431-436.

12 Conte RA, Pitter JH, Verma RS: Molecular characterization of trisomic segment 3p24.1->3pter: a case with review of the literature. Clin G enet 1995; 48: 49-53.

13 Stock C, A mbros IM, Mann G, Gadner H, A mann G, A mbros PF: Detection of $1 p 36$ deletions in paraffin sections of neuroblastoma tissues. Genes Chromosom Cancer 1993; 6: 1-9.

14 Vocero-A kbani A, Helms C, Wang JC et al: Mapping human telomere regions with $Y A C$ and $P 1$ clones: chromosome-specific markers for 27 telomeres including 149 STSs and 24 polymorphisms for 14 proterminal regions. G enomics 1996; 36: 492-506.

15 Sheehan C, Weiss A S: Y east artificial chromosomes: rapid extraction for high resolution analysis. N ucleic A cids Res 1990; 18: 2193.

16 A nand R, R iley J H, B utler R, Smith J C, Markham A F : A 3.5 genome equivalent multi access $Y A C$ library: construction, characterisation, screening and storage. Nucleic A cids Res 1990; 18: 1951-1956.

17 Lengauer C, Green ED, Cremer T: Fluorescence in situ hybridization of YAC clones after A lu-PCR amplification. Genomics 1992; 13: 826-828.

18 Pinkel D, Straume T, G ray J W: Cytogenetic analysis using quantitative, high-sensitivity, fluorescence hybridization. Proc Natl A cad Sci USA 1986; 83: 2934-2938.

19 Therkelsen A J, N ielsen A, K och J, H indkjaer J, K olvraa S: Staining of human telomeres with primed in situ labeling (PRINS). Cytogenet Cell G enet 1995; 68: 115-118.

20 G orinati $M$, Caufin D, M inelli A, M emo L, Gaspardo G, D odero A : Inv dup (8)(p21.1- > 22.1): Further case report and new hypothesis on the origin of the chromosome abnormality. Clin G enet 1991; 39: 55-59.

21 Flint J, Craddock CF, Villegas $A$ et al: Healing of broken human chromosomes by the addition of telomeric repeats. A m J H um G enet 55: 505-512.

22 Phipps ME, Latif $F$, Prowse $A$ et al: Molecular genetic analysis of the 3p-syndrome. Hum Mol Genet 1994; 3: 903-908.

$23 \mathrm{M}$ aher ER: Mapping of germline deletions in chromosome 3p25- >p26. Cytogenet Cell G enet 1995; 68: 145.

24 Knight LA, Yong $\mathrm{MH}$, Tan M, Ng ISL: Del(3)(p25.3) without phenotypic effect. J Med Genet 1995; 32: 994-995. 